\title{
Crímenes y humor en las novelas de Domingo Villar
}

\section{Crimes and humor in Domingo Villar's novels}

\author{
Javier Rivero Grandoso \\ Universidad Complutense de Madrid \\ Departamento de Filología Románica, Filología Eslava y Lingüística General \\ javierriverograndoso@filol.ucm.es
}

[Recibido, abril 2010; aceptado, maio 2010]

\section{RESUMEN}

En este artículo pretendemos poner de manifiesto la relevancia del humor en la obra de Domingo Villar. Nuestro objetivo es analizar las situaciones cómicas que crea el autor para poder descubrir de qué manera utiliza los elementos humorísticos y cuál es su finalidad. Nos parece fundamental atender a la configuración de los personajes y al recurrente uso de los estereotipos para mostrar la función del humor en Ollos de auga y A praia dos afogados, dos novelas muy bien valoradas por el público y la crítica.

PALABRAS CLAVE: Domingo Villar, género negro, novela policíaca, humor, Ollos de auga, A praia dos afogados

Rivero Grandoso, J., (2011): “Crímenes y humor en las novelas de Domingo Villar”. Madrygal (Madr.), 14: 109116.

\section{RESUMO}

Este artigo ten como obxectivo destacar a importancia do humor na obra de Domingo Villar. O noso obxectivo é analizar as situacións cómicas que crea o autor para descubrir os elementos humorísticos utilizados e a súa finalidade. Parece-nos esencial ter a configuración dos personaxes e do uso recorrente de estereotipos para mostrar o papel do humor en Ollos de Auga e A praia dos Afogados, dúas novelas moi apreciadas polo público e críticos.

PALABRAS CHAVES: Domingo Villar, xénero negro, novela policial, humor, Ollos de auga, A praia dos afogados

Rivero Grandoso, J., (2011): “Crimes e humor nas novelas de Domingo Villar”. Madrygal (Madr.), 14: 109-116.

\begin{abstract}
In this article we try to stress the importance of humor in the work of Domingo Villar. Our objective is to analyze the comic situations that the author creates in order to discover the humoristic elements used and the purpose of them. It is essential for us to study the configuration of the characters and the reoccurring use of stereotypes to discover the role of humor in Ollos de auga and A praia dos afogados, two novels highly appreciated by the public and critics.
\end{abstract}

KEY WORDS: Domingo Villar, crime story, humor, Ollos de auga, A praia dos afogados

Rivero Grandoso, J., (2011): “Crimes and humor in Domingo Villar's novels”. Madrygal (Madr.), 14: 109-116. 
Hace ya más de 25 años desde que Carlos G. Reigosa ganó la primera edición del Premio Xerais de Novela con Crime en Compostela, no sin polémica, pues una parte de la crítica consideraba que se trataba de una mimetización ingenua de un esquema narrativo extranjero (Vilavedra 2007: 7, 14). No obstante, otros estudiosos percibieron este premio como un estímulo, ya que

as múltiples polémicas producidas pola concesión do primeiro premio Xerais a esta obra confirmaban que o discurso literario galego comezaba a enfrontarse a novos desafíos, derivados dunha nova dinámica socioeconómica na que o mundo editorial xogaba un papel destacado (González Millán 1994: 163)

Y es que la novela de Reigosa fue la responsable de la adaptación a la realidad gallega de un género foráneo como era el género negro, que entraba por primera vez a una literatura que se enfrentaba, con la llegada de la democracia, a nuevos e importantes retos como la normalización y el asentamiento del ámbito editorial.

Tras diversos intentos de varios escritores de reafirmar el género en la literatura gallega, ha sido Domingo Villar, décadas después, el autor que ha revolucionado el panorama de la novela policíaca tras el sorprendente éxito de sus obras, que han sido traducidas a diversas lenguas. Con Ollos de auga, su debut en 2006, situó su nombre entre el de los escritores más vendidos. La novela, bien valorada tanto por la crítica como por el público, cuenta con nueve ediciones en gallego y dieciséis en castellano, además de varios premios. A praia dos afogados, publicada en 2009, fue la confirmación del interés que despierta en España la obra de Villar, pues también cuenta con múltiples reediciones. El escritor gallego ha sido destacado por pertenecer a una hornada de autores que dan «cierta frescura al género renovando en gran medida el clásico modelo de las generaciones anteriores en nuestro país» (Martín Escribà y Sánchez Zapatero 2009: 11).

Esta buena aceptación de los lectores y la crítica se debe en gran medida a la combinación de la intriga propia de una novela policíaca con otros elementos como la descripción del ambiente y el paisaje gallegos y el hilarante humor. De hecho, el propio Villar afirma que «la investigación policial no es más que una excusa para contar lo que sucede alrededor. También se puede conocer una sociedad a través de sus crímenes» (Rivero Grandoso 2011) En efecto, Villar profundiza en las costumbres y tradiciones de Galicia y en los personajes y las relaciones que estos mantienen entre ellos y con el entorno. La intriga policíaca es, en ocasiones, una excusa para explorar el comportamiento de las personas.

Es precisamente la construcción de la pareja investigadora lo que ha despertado un mayor interés entre los lectores por el contraste que en ella se produce. Esta está compuesta por el inspector Leo Caldas, el protagonista, y su compañero, el agente Rafael Estévez. Caldas es un policía de Vigo, lacónico y solitario, que vuelca todo su esfuerzo en realizar eficientemente su trabajo. En el trascurso de las dos novelas se da noticia de que terminó la relación que mantenía con Alba, una mujer a la que recuerda y de la que parece seguir estando enamorado, y cómo el trato con su padre no es muy fluido, con el que se ve sobre todo en $A$ praia dos afogados por la enfermedad del tío de Leo. En esta segunda novela, Villar profundiza mucho más en los personajes y en los vínculos que los unen ${ }^{1}$ : aparece Alba, de la que el lector solo tiene referencias en Ollos de auga, a través de una llamada de teléfono, aunque todavía no se ha mostrado físicamente; se narra el ambiente rural de las bodegas y las viñas del padre del inspector; continúa funcionando el Elixio como punto de encuentro; y crece la atención que se le presta a la personalidad compleja de Estévez.

Rafael Estévez, en oposición a Caldas, es un conflictivo agente aragonés que es trasladado a la comisaría de Vigo por los problemas que tuvo en su anterior destino. Aunque al principio no consigue adaptarse a un ambiente y a unas costumbres que le son del todo ajenas, paulatinamente, y un tanto forzado por las circunstancias, va comprendiendo la forma de ser del gallego. Sin embargo, el recurrente uso de la violencia se convierte en una fuente de conflictos en la que se ve inmerso también el inspector Caldas, que debe responder de su compañero.

Los crueles crímenes de las novelas de Domingo Villar quedan suavizados por un humor latente. Lois Reigosa, la víctima que desencadena la investigación de Ollos de auga, es asesinado después de

${ }^{1}$ Es comprensible si atendemos a la extensión de cada obra: Ollos de auga tiene 241 páginas, mientras que A praia dos afogados 504. 
que le inyecten en sus órganos sexuales una alta dosis de formol. El cadáver revela que Reigosa sufrió intensamente, pues el pene y los testículos están completamente negros y disminuidos por la abrasión del líquido. Lo desagradable de este asesinato, así como de los otros sucesos escabrosos que tienen lugar en la novela, se equilibra con las notas de humor que Villar inserta en su obra. Es el caso, por ejemplo, de Patrulla nas ondas, el programa de Radio Vigo en el que colabora el inspector Caldas. Se trata de una sencilla emisión radiofónica en la que los oyentes llaman para exponer un determinado caso al inspector, que, frustrado, ve cómo la mayoría de las peticiones debe solucionarlas la policía local. Caldas tiene que soportar que sea reconocido por los ciudadanos de Vigo como "el patrullero de las ondas", a pesar de que sus intervenciones en la radio no dejan de ser una anécdota en comparación con su duro trabajo diario. Es lo que le sucede en las investigaciones, lo que genera ciertas burlas de Rafael Estévez, que cree que los ciudadanos los atienden con mayor diligencia por ser tan popular. Caldas se sorprende también de que en el pueblo de su padre escuchen regularmente el programa, pues no pensaba que llegaran las ondas de Radio Vigo.

El presentador de Patrulla nas ondas es Santiago Losada, con el que el inspector no se lleva demasiado bien. Además de sus ridículas presentaciones, más propias de un combate de boxeo que de un programa radiofónico: «Está connosco o terror da delincuencia, o defensor implacábel do bo cidadán, o gardián temíbel das nosas rúas, o patrulleiro, o inspector Leo Caldas» (Villar 2006: 174); el inspector Caldas debe soportar que Losada inserte música mientras piensa posibles soluciones para las preguntas que le realizan los oyentes. A pesar de que el inspector no puede pensar con tranquilidad, el presentador continúa emitiendo los temas musicales después de que los ciudadanos hayan expresados sus problemas, y para colmo, los amigos de Caldas lo felicitan por la idea, que creen que fue de él mismo.

Los episodios narrados sobre el programa de radio tienen, además de la finalidad humorística, una intencionalidad crítica hacia la recepción de los medios de comunicación, que desvirtúan la labor, e incluso la identidad, del protagonista:

Todo el mundo conoce a Leo Caldas por su colaboración en las ondas, algo que molesta, y mucho, al inspector. Él podría llegar a aceptar el haber alcan- zado notoriedad por su trabajo en la comisaría, pero de ningún modo por acudir una vez por semana a un estudio radiofónico en el que oyentes enfurruñados denuncian asuntos que no le competen. Lo que me interesa a mí como autor es la tremenda exposición que proporcionan los medios de comunicación, que terminan por crear una realidad ilusoria. Si sales en los medios, eres lo que la radio, la prensa o la televisión proyectan de ti, no lo que realmente eres (Villar 2010: 66)

Pero, sin duda, el aspecto de las novelas que produce mayor humor está relacionado con la procedencia de los personajes: Domingo Villar asume los estereotipos y los tópicos propios de la persona gallega, e incluso, de la aragonesa, aunque esta última solo a través del agente Rafael Estévez.

Es Estévez un recurso que inteligentemente utiliza Villar para mostrar Galicia como algo nuevo a los ojos del lector. Por medio del agente aragonés se presenta la belleza del paisaje gallego, pues Estévez visita por primera vez esos lugares. Al ser el agente de una región del interior peninsular, se asombra ante la belleza de la costa gallega y la compara con los referentes que conoció en el pasado: «acostumado ao invariábel Mediterráneo, sorprendíalle a cantidade de praia que descubrirá o refluxo da marea» (Villar 2006: 100). Muchas cosas le resultan novedosas a Estévez y por eso llama la atención sobre ellas, como la belleza de los cementerios, distintos a los de su tierra, o su incomprensión de la mentalidad de las zonas costeras, pues se extraña cuando en una lápida lee la siguiente inscripción: "Aquí descansa Andrés Lema Couto, morto o 23 de xullo no mesmo mar que mo devolveu para darlle sepultura o 4 de agosto de 1981. A túa agradecida esposa estará sempre contigo» (Villar 2006: 95). Caldas le tiene que explicar que no está agradecida de que se ahogara en el mar, sino de que el mar devolviera el cuerpo, y así poderlo enterrar, lo que le evita a la familia el desasosiego de no saber a ciencia cierta lo que ocurrió con él.

Estévez es el que se enfrenta con la forma de ser gallega, recreada tópicamente, y a la que no consigue acostumbrarse. Su temperamento agresivo y su cabezonería son características que le dificultan enormemente su trabajo, como pronto se comprueba: si ya se rumoreaba que el agente aragonés llegó a la comisaría de Vigo por problemas de conducta, no van a ser menos sus percances en Galicia. Estos conflictos vienen ocasionados mayoritariamente por el choque que generan las diferentes costumbres y maneras de actuar pro- 
pias de cada pueblo. El narrador explicita las cosas a las que no se adapta Rafael Estévez en un párrafo en el que se presenta al personaje:

Rafael Estévez recalara en Galicia poucos meses atrás. O seu traslado debíase, segundo se murmuraba na comisaría, a un castigo imposto por alguén na súa Zaragoza natal. $\mathrm{O}$ axente aceptara sen especial desagrado traballar en Vigo, aínda que había varias cousas ás que lle estaba a custar un pouco máis tempo do previsto acostumarse. Unha era o impredicíbel do clima, en variación constante, outra a continua pendente das rúas da cidade, a terceira era a ambigüidade. Na recia cachola aragonesa de Rafael Estévez as cousas eran ou non eran, facíanse ou deixábanse sen facer, e supoñíalle un esforzo considerábel desenlear as expresións cargadas de vaguidades dos seus novos veciños. (Villar 2006: 16-17)

De esta manera, Villar esboza unos rasgos sociológicos de los gallegos muy cercanos a los tópicos que se mantienen en toda España: la indecisión, la ambigüedad, la costumbre de responder a cualquier pregunta con otra. Aunque a priori pueda parecer que el empleo de estos estereotipos produce una simplificación de la realidad y, por tanto, resta valor a las obras, lo cierto es que debemos recalcar que esta estrategia se emplea, fundamentalmente, de forma humorística, y no en todos los personajes, ya que, por ejemplo, Caldas no suele ser ambiguo con su compañero. De hecho, a través de las novelas de Villar se entiende que, si el tópico se cumple, es solo en parte, por lo que no es posible generalizar. Por otro lado, los personajes no responden a esquemas estereotipados, sino que están construidos de manera compleja, y a medida que transcurren las novelas, y es de esperar que siga así en las próximas entregas protagonizadas por Caldas y Estévez, el lector va conociendo más de ellos, por lo que aparecen más completos, con sus debilidades y sus pasiones.

Rafael Estévez está construido, salvando las largas distancias y con las diferencias necesarias para cumplir con la función para la que lo utiliza Villar, a semejanza del modelo del criado gracioso del teatro de la Edad de Oro, e incluso, de Sancho Panza. Estévez es el acompañante del protagonista no solo debido al cumplimiento de un requisito de verosimilitud, ya que la policía trabaja generalmente en parejas, sino también como recurso narrativo para establecer el diálogo con Caldas, a la manera cervantina, o, citando a los clásicos policíacos, como Sherlock Holmes y Watson o Hercule Poirot y Arthur Hastings. Sin embargo, el humor que aporta a las obras el personaje de Estévez no se debe, como ocurría frecuentemente en la Edad de Oro, a la ignorancia o a la picaresca del personaje, sino que se trata más bien de las diferentes personalidades basadas en la procedencia de los individuos.

En efecto, Estévez es un poco bruto, y esta característica se ve acentuada por su físico, ya que el agente es bastante alto y corpulento. Pronto se explica que el agente aragonés tiene serios problemas para controlar su agresividad, que aparece principalmente cuando las personas a las que interroga no responden directamente a las preguntas que les hace. Al principio de Ollos de auga aparece, para demostrar la rapidez con la que el agente pierde los nervios, un altercado bastante cómico en el que interroga a un adolescente que detuvieron por vender marihuana: Estévez intenta tomarle los datos, pero poco a poco se va desesperando al ver que debe insistir y plantear varias preguntas para encontrar una respuesta satisfactoria cuando le pide al joven el nombre, los apellidos, el domicilio en el que vive, etc. El agente, sin tener en cuenta que el interrogado es un muchacho acusado de un delito menor, se harta de que le responda solo con preguntas y lo levanta del suelo agarrándolo por la chaqueta y lo amenaza metiéndole la pistola en la boca.

Ante este escandaloso caso de brutalidad policial, el comisario decide que Estévez trabaje con el lacónico Caldas, un hombre mucho más tranquilo, prácticamente un polo opuesto al aragonés: forman así una extraña pareja, que, según muestran los resultados, parece ser eficiente, aunque con multitud de diferencias entre ellos. Una de ellas se convierte en motivo de discusión en $A$ praia dos afogados, pues Caldas hace trabajar a Estévez el fin de semana, a pesar de que este ya tenía planes. Estévez le recrimina que él sí tiene vida, no como el inspector, que tras terminar su relación con Alba se dedica por completo a su trabajo.

La vida de Leo Caldas se sustenta principalmente en la resolución de los casos y en la participación semanal en el programa radiofónico. Villar construye un personaje solitario y un tanto apático, con pocas personas a su alrededor, que son principalmente su padre, con el que mantiene una relación algo áspera, sin un trato excesivamente fluido, aunque en la segunda novela intiman más por la enfermedad del tío de Leo, Alberte; y Carlos, el dueño de la taberna Elixio. Aunque Leo está unido afectivamente a estos dos hombres, es una persona cerrada que no muestra sus sentimientos, de tal forma que vive por y para su trabajo. 
Caldas no logra apaciguar por completo a su compañero, que pierde los nervios durante el interrogatorio a María de Castro Raposo, la señora de la limpieza de Lois Reigosa y la que encontró el cadáver de su jefe, y tiene que ser sustituido por el inspector.

Las quejas de Estévez por la ambigüedad gallega se vuelven recurrentes y famosas entre sus compañeros de trabajo, por lo que Caldas se acostumbra a lidiar con su mal humor, como ocurre en este caso con el doctor forense Barrio:

-Sabemos como morreu? -interrogou Rafael Estévez dirixíndose ao doutor.

-Reigosa? -preguntou Guzmán Barrio.

-Non, Lady Di - cortou Estévez.

-Non fagas caso, Guzmán, Rafael é así de simpático -interveu Leo Caldas, reprendendo ao seu axudante cunha mirada censuradora-. Xa sabes como morreu? (Villar 2006: 33)

Estévez también se toma con humor la situación, principalmente con una ironía ácida que hace patente el desagrado que siente ante la situación que se le plantea. Si en esta ocasión le molesta la innecesaria pregunta, más tarde hará alusión a la manía de los gallegos de responder con una interrogación en un hospital en el que no guardan los datos de las personas que pueden tratar con el formol:

-Entón pode vir calquera e levalo sen deixarlles os seus datos.

-Si, aquí non preguntamos.

-Pois deben ser os únicos -murmurou Rafael Estévez, que permanecía detrás do inspector. (Villar 2006: 123-124)

Pero si Estévez muestra su antipatía con la forma de ser del gallego, la venganza la provocan cómicamente los animales. En dos momentos de Ollos de auga un perro y una faneca la toman con Estévez, lo que crea dos situaciones bastante graciosas que confirman al agente aragonés como principal fuente de humor de las obras. En la primera, el perro de Isidro Freire, un hombre que trabaja como responsable de zona de una empresa que suministra formaldehído, se ceba con los zapatos del agente hasta que consigue arrancarle un cordón; en la segunda, Estévez se baña en la maravillosa playa de Lapamán, de la que dice que «isto é o paraíso» (Villar 2006: 100), pero poco tiempo después de sumergirse en el agua una faneca brava le deja muy dolorido el pie.
Estévez vuelve a ser el centro de la hilaridad de las obras, ya que aparece como un personaje inadaptado, y despierta cierta compasión que permite que el lector pueda perdonar sus airados arranques de violencia. Precisamente estos arrebatos también poseen un indudable componente humorístico, a pesar de la gravedad de los hechos que se narran.

Uno de estos sucesos se produce como consecuencia del daño que le hizo la faneca a Estévez en el pie: Caldas y él visitan el Idílico, un pub del Arenal al que acude principalmente público homosexual, para seguir una pista sobre el asesinato de Lois Reigosa. Allí, mientras el inspector indaga, el agente se queda en una mesa por el dolor que siente. El altercado se inicia cuando un joven se acerca a Estévez para ligar y le acaricia el pie desnudo: entonces, el aragonés le propina un puñetazo al muchacho que le rompe la nariz.

Caldas foi na busca do seu axudante e mais da súa cervexa. Viu, ao fondo, un tumulto no medio do cal destacaba Rafael Estévez alzándose un palmo por enriba dos demais. Brandía a pistola nunha man e o zapato na outra, e bradaba encolerizado, totalmente fóra de si. A distancia, o volume da música e o balbordo fixeron que Leo tivese que achegarse uns pasos até distinguir as palabras do axente.

-Quen se acerque a menos de dous metros é home morto! (Villar 2006: 121)

Caldas debe proteger a su compañero y encubrirlo ante el comisario Soto, incluso cuando un representante del colectivo homosexual llama a la radio durante la emisión del programa Patrulla nas ondas para censurar el incidente y exigir responsabilidades por la actuación de Estévez, a la vez que lo felicita y lo alaba por su heroísmo al defender a los hombres que se encontraban en el local.

Este suceso ocurrido en el bar de ambiente produce una sonrisa en el lector, que imagina al bruto y enorme agente empuñando la pistola para alejarse de los demás hombres, a la vez que provoca una mirada reprobatoria ante la latente homofobia de este personaje, nada sorprendente, por otro lado, pues ya ha mostrado sobradamente su actitud de enfado ante lo desconocido y ante lo que no le gusta y su constante agresividad. Más tarde también pierde los nervios en una cafetería en la que está con el inspector. Tras discutir entre ellos, Estévez se enfada con el camarero porque no le trae el hielo que le ha pedido para su coca-cola. Este le explica insistentemente que no necesita hielo, ya que el refresco lo acaba de sacar del frigorífico, y el agen- 
te, indignado porque el camarero no le hace caso, lo zarandea por el cuello:

-Eu o xeo tráiollo. Pero mire que fresquiña está. Estévez púxose de pé, agarrou o camareiro polo pescozo e comezou a abanealo.

-Quéroa con xeo, con moito xeo! Entendiches? -bradaba colérico-- Galego testalán, cabezón, fillo de puta!

Leo Caldas saltou sobre o brazo do seu iracundo axudante.

-Rafa, estás tolo ou que carallo che pasa. E vostede -ordenou-, quere ir polo xeo dunha vez? Está máis chalado aínda ca el. (Villar 2006: 168)

En A praia dos afogados Domingo Villar no centra el humor tanto en la ambigüedad gallega como en las supersticiones de los habitantes de Panxón. El escritor hace referencia, así, al mundo del más allá, al temor a lo desconocido, a las fuerzas sobrenaturales, a la atmósfera misteriosa recurrentemente relacionada con Galicia por sus tradiciones. Y de nuevo es Estévez, el foráneo incapaz de comprender las creencias del pueblo pesquero, el que introduce en la narración el humor.

Desde hace semanas los vecinos de Panxón sospechan que el fantasma del capitán Sousa, patrón del barco hundido Xurelo, pasea por el pueblo. Se da la circunstancia de que la víctima del caso que investigan los agentes, Xusto Castelo, había trabajado, junto con dos hombres más, en el mismo barco en el que pereció Sousa hace doce años. Los policías descubren que Castelo también debía estar asustado por ello, pues cuando encontraron el cadáver portaba una bolsita con sal y una higa para espantar a los espíritus. Además, cuando a los pescadores se les nombra a Sousa, enseguida, para protegerse del fantasma, tocan hierro y escupen, algo que Estévez no espera:

-Estanos a falar dunha pantasma, dun aparecido? - preguntou o inspector.

Como nun ritual, Hermida golpeou coa man pechada unha das patas metálicas da mesa e cuspiu no chan.

-Toca ferro - falou entre dentes.

-Pero vostede que fai? -exclamou Rafael Estévez poñéndose de pé dun brinco.

-Tranquilo, Rafa - tratou de serenalo o inspector-. Nin que che botase un mal de ollo.

-Que mal de ollo nin que collóns! -voceou indignado o aragonés, mentres buscaba un pano de papel nunha mesa veciña-. Cuspiume nun zapato. (Villar 2009: 108)
La duda sobre la veracidad de la existencia del fantasma de Sousa se instala en Caldas: comparte, en cierta medida, la misma mentalidad de los pescadores, ya que, si bien no confiesa abiertamente sus temores al comisario Soto, tampoco descarta esa posibilidad. Son, sin embargo, los personajes foráneos (además de Soto) los que niegan rotundamente cualquier indicio que apunte a un fantasma: la mujer del sospechoso Valverde, madrileña, y el agente Estévez no pertenecen a ese mundo conformado por meigallos y conxuros tan propio de Galicia, por lo que no creen en apariciones.

Las supersticiones de los pescadores también son fuente de conflicto para Rafael Estévez, que, cuando no tiene cerca la vigilancia de Caldas, saca a relucir su agresividad. En este caso, a la costumbre de escupir para espantar el mal fario se le une la ambigüedad tan odiada por el aragonés:

-A min contáronme algo dun pescador que tivo un incidente cun policía esta mañá no porto. Pódese saber que carallo sucedeu?

-Xa lle contei que me cuspiu, inspector. Que quería, que liscase sen máis?

-Dixéchesme que non lle fixeras nada.

-Non, non..., o que lle dixen é que me deron ganas de tiralo ao mar e ben sabe Deus que me contiven.

-Pero pegácheslle...

- Coa mano aberta -tratou de xustificarse Estévez, coma se o pescador tivese que agradecerlle recibir un lapote no canto dunha combinación de golpes co puño pechado-. Puxéronme histérico, non había xeito de que contestasen ao que lles estaba a preguntar. (2009: 178-179)

El humor es, pues, un componente esencial en las novelas de Villar. Si atendemos a la diferenciación de lo cómico que establece Morera para referirse al humor en la obra de Unamuno y en la de Cervantes, «de manera puramente lúdica o constructiva, destacando sobre todo el lado divertido o alegre de las cosas, sin malicia, o de manera hipercrítica y destructiva, ridiculizando el objeto que se analiza, sea o no con una finalidad superior» (2006: 52), podemos concluir que Villar lo emplea de un modo similar al de Cervantes, sin un interés marcadamente crítico. La intención del autor gallego es divertir al lector, y estas escenas humorísticas sirven de contrapunto a la seriedad y el dramatismo propio de los crímenes que se relatan. Así se rebaja la tensión asociada a una narración de intriga, con el elemento cómico como recurso que escogen muchos de los escritores españoles actuales de novela policíaca. 
En la obra de Villar el humor no tiene como finalidad desacreditar a un determinado personaje o servir como crítica a alguna cuestión concreta. Se trata, más bien, de una mirada amable a las situaciones cotidianas de unos personajes que pueden resultar cómicas, como sucede con la participación de Caldas en la radio; o de la hilaridad que produce el choque cultural al que se enfrenta Rafael Estévez. El agente aragonés es trasladado a Galicia y no consigue adaptarse a las costumbres y a la mentalidad del lugar, tan diferentes a las de su región. Al no comprender unos códigos culturales que le son ajenos, Estévez, caracterizado por una agresividad manifiesta, ocasiona multitud de conflictos y malentendidos que generalmente intenta arreglar mediante el uso de la violencia. Estas situaciones, representadas principalmente a través del diálogo y de las acciones realizadas por el aragonés, están cargadas de humor, y, aunque muchas veces el comportamiento de Estévez sea censurable, las escenas que se narran no humillan ni pretenden ridiculizar al compañero de Caldas ${ }^{2}$.
Por la tanto, la intención de Villar no es satirizar al personaje ni mucho menos las costumbres gallegas, sino mostrar la mentalidad de esta región a través de la mirada de un personaje foráneo, que puede señalar y sorprenderse por las diferentes maneras de ser y de comportarse respecto a su lugar de origen. Para ello el escritor asume los estereotipos ligados a Galicia, y lejos de criticarlos, los defiende como parte de la composición de sus personajes y los contrasta con Estévez, el personaje aragonés que se ve de repente frente a los tópicos gallegos que le cuesta tanto soportar.

Es la acertada mezcla de elementos humorísticos, de intriga y de tensión lo que ha convertido a Domingo Villar en uno de los autores más prometedores del género. Con su capacidad para conseguir crear una misteriosa trama policíaca e ingeniosas situaciones cómicas ha logrado adueñarse de la atención del público y de la crítica, que esperan ávidos la tercera entrega de las aventuras protagonizadas por Leo Caldas y Rafael Estévez.

\section{REFERENCIAS BIBLIOGRÁFICAS}

GonZÁlez Millán, Xoán (1994): Literatura e sociedade en Galicia (1975-1990). Vigo: Xerais.

MARTín EsCRIBÀ, Ảlex, y SÁNCHEZ ZAPATERO, Javier (2009): «Nuevos culpables del policial español», en La lista negra. Nuevos culpables del policial español. Madrid: Editorial Salto de Página, pp. 5-13.

Morera, Marcial (2006): «Humor unamuniano vs. humor cervantino. Comentario de texto», en Cuadernos de la Cátedra Miguel de Unamuno, № 41. Salamanca: Ediciones Universidad de Salamanca, pp. 51-61.

Rivero Grandoso, Javier (2011, en prensa): «Entrevista a Domingo Villar», en La Página, № 89, Tenerife.

VILAVEDRA, Dolores (2007): «Para una cartografía de la narrativa gallega actual», en Letras Hispanas: Revista de Literatura y Cultura, Volume 4, Issue 1, pp. 7-15.

VILlar, Domingo (2006): Ollos de auga. Vigo: Galaxia.

(2009): A praia dos afogados. Vigo: Galaxia.

(2010): «Literatura de fermentación lenta», en Realidad y ficción criminal. Dimensiones narrativas del género negro, MARTín EsCRIBÀ, Àlex, y SÁNCHEZ ZAPATERO, Javier (eds.). Valladolid: Difácil, pp. 63-70.

\footnotetext{
${ }^{2}$ Hay momentos realmente cómicos en los que se muestra que Estévez es un poco simple, como en el capítulo en el que el agente comenta al inspector lo buenos que estaban los percebes que compraron a unos jóvenes. Caldas, bromeando, le pregunta si le quitó la piel, a lo que el aragonés contesta que «Claro [...] A partir do segundo si» (Villar 2009: 363). A pesar de que Estévez no queda muy bien parado, se podría justificar por el desconocimiento que este personaje tiene de este producto tan típico de Galicia, pues en unas páginas anteriores Caldas le ha explicado cómo se cocinan.
} 
